\section{Fatal massive air embolism following diagnostic colonoscopy}

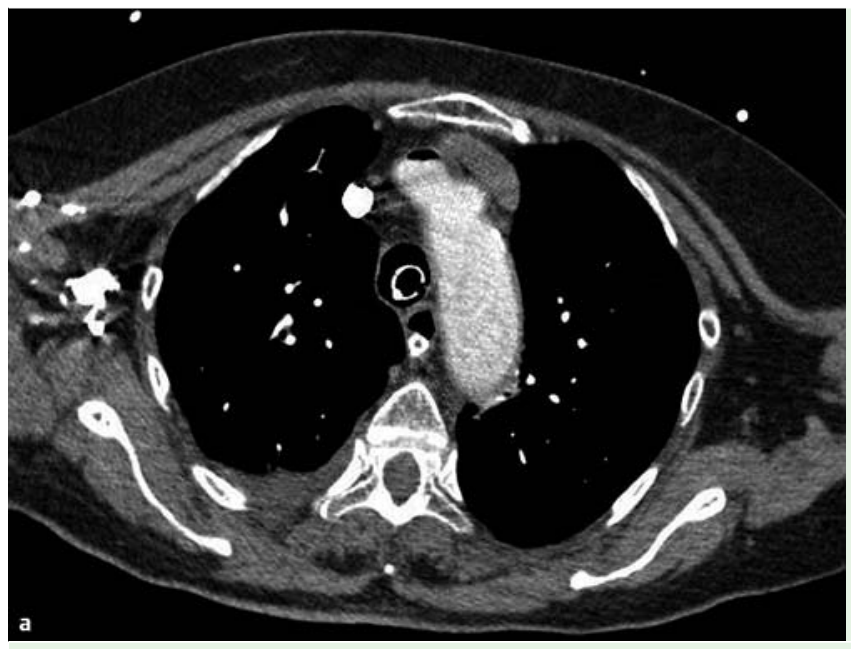

Fig. 1 a CT of the chest, showing air in the aortic arch. b CT of the abdomen, showing air in the venous circulation (splenic and portal veins).

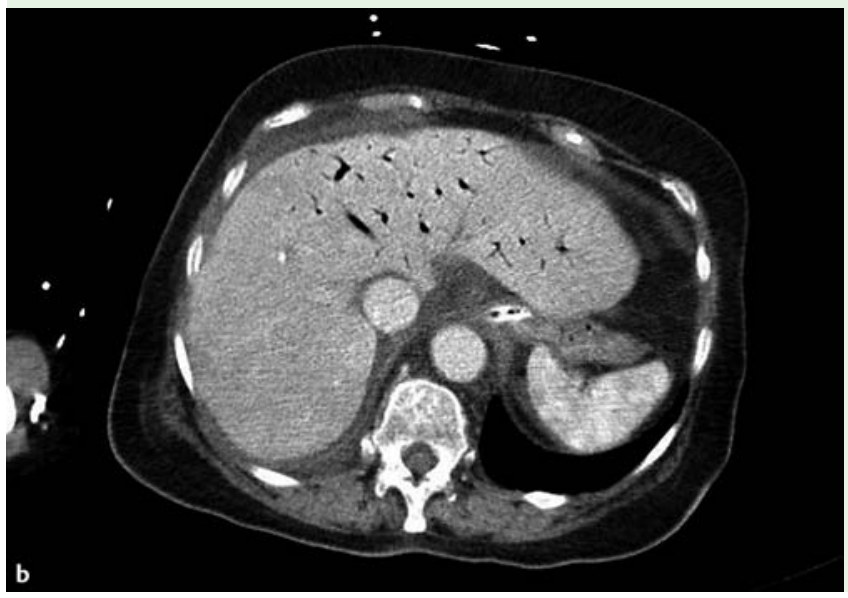

Air embolism [1,2] is a rare complication that occurs following a wide range of diagnostic and therapeutic invasive procedures. Only six cases of air embolism following colonoscopy have been reported and all occurred in patients with underlying colonic pathology.

We present a case of an 83-year-old woman who underwent colonoscopy for evaluation of rectal bleeding. Colonoscopy was incomplete due to angulation and narrowing of the colon at $25 \mathrm{~cm}$ from the anal verge. Computed tomography (CT) colonography revealed bowel thickening suggestive of sigmoid cancer. The patient then underwent another colonoscopy under deep sedation, but several attempts to complete the examination with a colonoscope and a gastroscope were unsuccessful. Immediately after this colonoscopy, the patient was unresponsive, cyanotic, hypotensive, with dilated jugular (atrial shunts). investigation [3], it should be considered in patients presenting neurological symptoms or hemodynamic instability. Initial management involves aspiration of the insufflated air, and Trendelenburg's and Durant's maneuvers. It is vital to provide treatment comprising vasoactive drugs, fluid resuscitation, mechanical ventilation, and high-flow oxygen. In case of arterial air embolism early hyperbaric therapy is the treatment of choice [4]. Hemodynamically unstable patients with air outflow obstruction of the right ventricle and pulmonary arteries may benefit from intracardiac aspiration and closedchest cardiac massage.

Endoscopy_UCTN_Code_CPL_1AJ_2AB

Competing interests: None

\section{J. Sopeña-Falco ${ }^{1}$, N. Poch-Vall ${ }^{2}$, \\ E. Brullet ${ }^{1}$, H. Mendez-Reyes ${ }^{2}$, \\ E. Martínez-Bauer ${ }^{1}$, F. Junquera ${ }^{1}$, \\ G. Pujol-Caballe ${ }^{2}$, R. Campo ${ }^{1}$}

1 Digestive Diseases Department, Corporació Sanitaria Parc Tauli, Sabadell, Spain ${ }^{2}$ Anesthesiology Department, Corporació Sanitaria Parc Tauli, Sabadell, Spain

\section{References}

1 Muth CM, Shank ES. Gas embolism. N Engl J Med 2000; 342: 476-482

2 Nossum $V$, Hjelde A, Brubakk A. Small amount of venous gas embolism cause delayed impairment of endothelial function and increase polymorphonuclear neutrophil infiltration. Eur J Appl Physiol 2002; 86: $209-214$

3 Ha JF, Allanson E, Chandraratna H. Air embolism in gastroscopy. Int J Surg 2009; 7: 428 430

4 Jorgensen TB, Sørensen AM, Jansen EC. Iatrogenic systemic air embolism treated with hyperbaric oxygen therapy. Acta Anesthesiol Scand 2008; 52: 566-568 tion (CPR) was initiated. After 3 minutes of CPR, the patient regained stable sinus rhythm. Urgent echocardiography was carried out but visualization of the right chambers was incomplete. CT chest and abdomen ( Fig.1) demonstrated the presence of air in the venous circulation, right heart, aorta, and signs of pulmonary hypertension. Despite resuscitation, the patient's clinical condition deteriorated with fatal outcome 10 hours later. The autopsy revealed two ulcers in the transverse colon with no sign of perforation, cancer, or cardiovascular malformations

Although air embolism is an extremely rare complication following endoscopic
Bibliography

$10.1055 / \mathrm{s}-0032-1326254$

Endoscopy 2013; 45: E91

(c) Georg Thieme Verlag KG

Stuttgart $\cdot$ New York

ISSN 0013-726X

Corresponding author

J. Sopeña-Falco

Digestive Diseases Department

Corporacio Sanitaria Parc Tauli

Sabadell

Spain

gulab2132@yahoo.es
Dol http://dx.doi.org/ 